\title{
The Impact of Digital Technology on Network Value Co-creation
}

\author{
Sarah Hönigsberg \\ Chemnitz University of \\ Technology, \\ sarah.hoenigsberg \\ @,wirtschaft.tu-chemnitz.de
}

\author{
Barbara Dinter \\ Chemnitz University of \\ Technology \\ barbara.dinter \\ @, wirtschaft.tu-chemnitz.de
}

\author{
Hendrik Wache \\ Chemnitz University of \\ Technology \\ hendrik.wache \\ @,wirtschaft.tu-chemnitz.de
}

\begin{abstract}
In recent years, the discussion about how companies integrate new technologies into their value creation and how this affects their business has intensified. The trend towards digitalization is particularly challenging for smaller, value co-creating (VCC) companies in networks, yet little research has been done in this context. In response, this paper identifies four key technologies for promoting network VCC: (1) a service configuration system, (2) a centralized knowledge base, (3) an analytics system, and (4) a shared IT platform. We conducted a single embedded case study in a company network introducing these key technologies and thereby digitally transforming its VCC. Our results show how the companies in the network are approaching their transformation and what the impact and role of the technologies in their network VCC are.
\end{abstract}

\section{Introduction}

Nowadays, companies are confronted with the fact that more and more new technologies are available for enhanced customer engagement. For example, Legner et al. [21] discuss the convergence of so-called SMAC technologies - social, mobile, analytics and cloud computing - that leads to a massive wave of digitization resulting in innovations in business and society, e.g. by new opportunities of customer engagement. The concept of customer engagement describes the cognitive process a customer experiences when e.g. interacting with a brand and is connected to the value co-creation (VCC) between a firm and a customer [7]. In this context, besides traditional websites and social media platforms, toolkits (e.g. configurators), which are specially designed to digitally facilitate the customer engagement in the VCC process, are discussed [11]. It is important that the customer in the VCC discussion can refer to any kind of customer including business customers [30].
Thus, we prefer the term actor engagement to avoid confusion since this paper is exclusively about VCC in the context of business-to-business (B2B). In recent years, the VCC discussion has shown that the principle of a dyadic approach (as customer-firm interaction) must be transferred to company networks (as manycompany-company interaction) in order to be able to cover the VCC between businesses properly [1]. The company networks are often comprised of small and medium-sized enterprises (SME) with many B2B relationships. They constitute a large part of the economy, and are often underestimated in their innovative capacity [8]. The issue of engagement is very relevant in the B2B-based network VCC and questions arise of how established as well as new technologies can be applied in this area and what role they play in enhancing the VCC through the engagement of actors [4]. For example, Lusch and Nambisan [22] identify the following as an open research question about their service platform for network VCC: "In what ways can digital resources (components) be configured/developed so that they could assume an active or triggering (i.e., operant) role in service innovation?" In this regard, it is important to note that the introduction of new technologies triggers a process of change that companies must manage [21]. In other words, introducing new technologies in a B2B network to improve the VCC leads to a digital transformation of the whole VCC network. The interplay of the introduction of new technologies and the network VCC, especially for SME, is little explored, and is, therefore, seen as a research gap. This is where our research intends to commence and to answer the question: How do company networks introduce new technologies for enhanced VCC and how do these technologies impact the network VCC? By answering this question, we contribute to the research about technology utilization in VCC and offer practical examples of how the transformation of VCC in SME networks can be realized.

The paper at hand outlines which technology components are essential for the improvement of VCC in the theoretical foundations, followed by the research 
approach. A case study then shows how an SME network initiates the different essential technologies through several initiatives (in the sense of small implementation projects). In the discussion, we examine the impact of the initiated transformation on their network VCC and the role the technologies play in it. The paper ends with a summarizing conclusion.

\section{Theoretical Foundations}

\subsection{VCC in SME Networks}

In the past decades, markets have changed significantly and companies are confronted with customers who expect personalized experiences. 2004, Prahalad and Ramaswamy [28] described how customers are dissatisfied with the choices available and want to interact with the companies and co-create value. This changes the process of value creation and consumer-business interaction becomes the locus of joint creation, which is called VCC [28]. In the traditional view, VCC is a dyadic, collaborative process between actors. Companies form valuenetworks in order to reduce potential risks and to gain a competitive advantage by focusing on their key competencies [19]. This leads to higher productivity in the network but also increases the need for interorganizational communication and coordination in the VCC [19]. SME with their limited resources are particularly affected by this trend towards the organization in networks [23]. In VCC, bigger companies often overpower smaller companies and the smaller companies are overdependent. A SME network is comprised of more equal actors, which leads to a loosely coupled network based on agreements [26]. The dyadic VCC perspective needs to be broadened to a network perspective. The VCC in actor networks is typically discussed together with the service-dominant logic (SDL). The SDL is a theoretical framework, which allows to abstract from the tangibility or intangibility of resources in exchange. It defines all application of competencies for the benefit of another as service, and focuses the process, not the output, as value creation [34]. From this viewpoint, the VCC occurs in an actor-to-actor (A2A) network in which each actor can be a beneficiary and the VCC is thus a process that flows through the entire network [22]. Most industries are becoming increasingly knowledgeintensive [25], making knowledge one of the most valuable resources in the VCC [35] and include joint problem solving as VCC [1].

A convergence of the two subject areas VCC and digital transformation can be observed. While the VCC discourse underlines the importance of new technologies, particularly for actor engagement in value creation [4], the digital transformation discourse on the other side emphasizes that the strategic transformation of companies inevitably leads to networking, to actor engagement, and to competitors becoming partners [31]. The increasing importance of IT as the enabler of the VCC is also highlighted in the paper by Lusch and Nambisan [22], in which they address the operand, the operant or the triggering role of IT in this context. It can be seen that web technologies in particular, are a frequent subject of discussion in combination with $\mathrm{VCC}$, as they enable the linkage of many actors [33]. These web technologies range from simple web pages to online product configurators to virtual worlds.

Another research area where joint value creation and the experience of it is also discussed frequently is mass customization (MC). MC represents a cross-over of classical differentiation and cost leadership, where custom-made products are manufactured with the efficiency of mass production [32]. Although MC has a more technical side of producing customized products in the most efficient way, there is the other side of this research debate, where the role of the engagement of the customizing person is in the focus [11]. Originally, VCC was strongly separated from MC as the latter focused too much on supply chain optimization rather than joint value creation [28]. Nevertheless, even then, $\mathrm{MC}$ was regarded as the most advanced application of actor engagement in some areas of new product development [33]. In this sense, MC is also interpreted as a possible implementation of VCC [27] and therefore boundaries in the discussions of actor engagement are becoming seamless. This leads to our conclusion that the technologies and mechanisms discussed in the context of MC's customer integration are also relevant for actor engagement of the VCC.

\subsection{Essential Technologies to Enhance VCC}

We base the identification of the essential technologies that can foster VCC in company networks on two research foundation perspectives. The first research foundation perspective we take into account is about prominent digital technologies for actor engagement in the field of MC. The second research foundation perspective is about VCC with its theoretical connection to SDL. In order to build on previous findings from our research, our conceptual framework based on four propositions is included in addition to the basic literature. It states [16]: (1) The internal value creation processes must be modular so that the individual process steps can be combined between actors using defined interfaces, (2) all actors in the VCC process in the network are equal 
participants, (3) efficient and preferably standardized communication between the actors for the transfer of information and knowledge must be established in order to reduce information asymmetry, and finally, (4) there must be a cross-organizational IT support for the modular VCC process in the network, which allows the actors equal access to liquefied resources (information decoupled from physical carrier). These fundamentals are combined to identify the most important technologies to foster network VCC.

The most discussed technology in the context of $\mathrm{MC}$ is the product configurator. This interaction system is intended to facilitate the complex task of configuration for humans [40]. Product configuration is a particular type of design activity and a subclass of configuration in general. The product to be designed consists of a set of predefined components that can only be combined in a certain way, with the set of possible combinations constituting the solution space [24]. The product configurator guides the customer through the configuration process to help her/him to co-create [10]. Each actor can take on the role of the configuring designer in the VCC in an A2A network. Lusch and Nambisan [22] describe how new services are configured by mixing and matching existing knowledge components or resources. The abovementioned proposition (1) also addresses this fact: The internal value creation processes must be modular so that the individual process steps can be combined between actors in the network, to allow the configuration of new solutions. This leads to our first essential technology to support the VCC in networks, the service configuration system, which allows the (re-)configuration of tangible and intangible resources.

The product configuration as one of the key activities in $\mathrm{MC}$ is a knowledge-intensive process. In this context, there is much discussion about the acquisition and representation of domain knowledge [40]. The systems contain or need direct access to knowledge bases with product knowledge and configuration rules [3]. Knowledge is not only seen as a fundamental resource in the MC discourse. Operant resources (like knowledge) are the fundamental source of strategic benefit from an SDL perspective [36]. In the context of knowledge-intense VCC, AarikkaStenroos and Jaakkola [1] emphasize that expert knowledge is paramount and that applying knowledge to value creation acts as an amplifier. In combination with our proposition (3), efficient and standardized communication between the actors, we propose a centralized knowledge base as one of the essential technologies of the VCC in networks.

Regarding customer interaction in the MC context, the topic analytics is often mentioned. In fact, configuration systems are regarded as one of the earliest commercially used applications of artificial intelligence (early representatives in the late 1970s) [40]. One of the most frequent applications of analytics in this context is to determine the best possible configurations or to make recommendations to the user based on specified requirements. A frequently discussed approach to give recommendations is casebased reasoning, which retrieves the best fitting solutions from a case database [3] via case similarities. From a SDL perspective on a service ecosystem, the importance of decision support through so-called cognitive computing is growing, since decision making by actors is supported or replaced using modern analysis methods [36]. Due to the increasing importance of analysis support in the digital era and in conjunction with proposition (3), we suggest an analytics system as one of the essential technologies.

As discussed by von Hippel [14], exchange platforms and even user communities are important tools for customer integration. In the MC literature, the classic product configurator is also associated with communities and comprehensive platforms in order to be able to offer higher-value interaction platforms for the customer [9]. Kristianto et al. [20] also show how a platform shared in the supply chain can be designed with a knowledge base and a configurator in the engineer-to-order (ETO) configuration area for boats. From the perspective of the VCC, however, these physical or virtual customer touchpoints where actors exchange resources and co-create value are known as engagement platforms [4]. Our proposition (2) demands that all actors in the $\mathrm{VCC}$ process in the network can be equal actors (no hierarchy or overpowering) and our proposition (4) requires that cross-organizational IT support makes it possible to manage the modular VCC process and give access to important resources. This leads to our last essential technology, a shared IT platform, providing the other essential technologies as well as the interaction and communication means for all actors in the network.

\section{Research Approach}

To answer the question of how company networks introduce new technologies for enhanced VCC and how these technologies impact the network VCC, the paper at hand presents a contemporary study in the German textile industry. As already mentioned above, the topic of VCC in B2B networks and especially the influence of new digital technologies have not yet been sufficiently investigated. In order to gain a deeper understanding of insufficiently studied subjects, Corbin and Strauss [6] suggest conducting qualitative research to holistically and comprehensively explore the chosen 
phenomenon. As stated by Yin [39], a case study is such a qualitative, empirical method that examines a contemporary phenomenon in its depth and in its real context, and is particularly appropriate when the boundaries between the phenomenon and the context are unclear.

To examine a network as a case, at least three companies forming a network are needed as multiple units of analysis (UA). Due to the complexity of network research single case studies are often preferable, to guarantee in-depth insights [13]. This leads to our study design of a single embedded case study. As a sample, we have chosen a network which faces digital transformation in a low-tech industry, as a typical representative of a change in an entire industry (common case). We have opted for an in-depth and long-term (summer 2017- till now) study of this network in order to be able to observe the companies' approach to the introduction of new digital technologies and the effects of the transformation on the network VCC. All four companies are highly specialized SME. They have successfully focused their business on the niche of knowledge-intensive technical textile processing and no longer focus on lowknowledge home textiles. They build a dynamic A2A network in which they exchange services, which means that a suitable network configuration is created to handle each customer order. The companies share a portfolio together and collaborate frequently in the real world in production and new product development (ETO approach). The network customers are exclusively other companies (e.g. car manufacturers). This means that the network partners form a B2B virtual company (as it is sometimes called in the textile industry context [15]) and serve the network customers also in a B2B relationship. The examined network is comprised of a weaving factory, a knitting factory, a textile coater, and a textile finisher. The sampling was made in a way, that the involved companies represent different stages in textile value creation or are substitutes for each other, which reflects a typical situation in this industry where companies collaborate and compete in the network at the same time [15].

For our data collection, five different instruments were used to be able to triangulate robust findings [39]: four questionnaires, four direct observations, two joined workshops with all companies, 19 interviews, and document analysis of ordering forms, product, prototype, and internal process documentation. We collected the data in an iterative way so that the findings from previous data collection rounds could be integrated into subsequent data collection (cf. [16]), as shown in Figure 1. In most data collection rounds, the companies were examined separately. All results presented in this paper have been translated from German to English and have often been consolidated to a more general statement for all companies. Furthermore, the UA are not always connected with single observations, since that could make them identifiable. The analysis step of our case study is divided into first level and second level analysis (cf. Figure 1). Whereby the first level represents the evaluation, coding, and triangulation between the data collection rounds and the second level is the analysis of the results according to the essential technologies to enhance VCC. Figure 1 shows how we leverage different perspectives to identify the essential technologies.

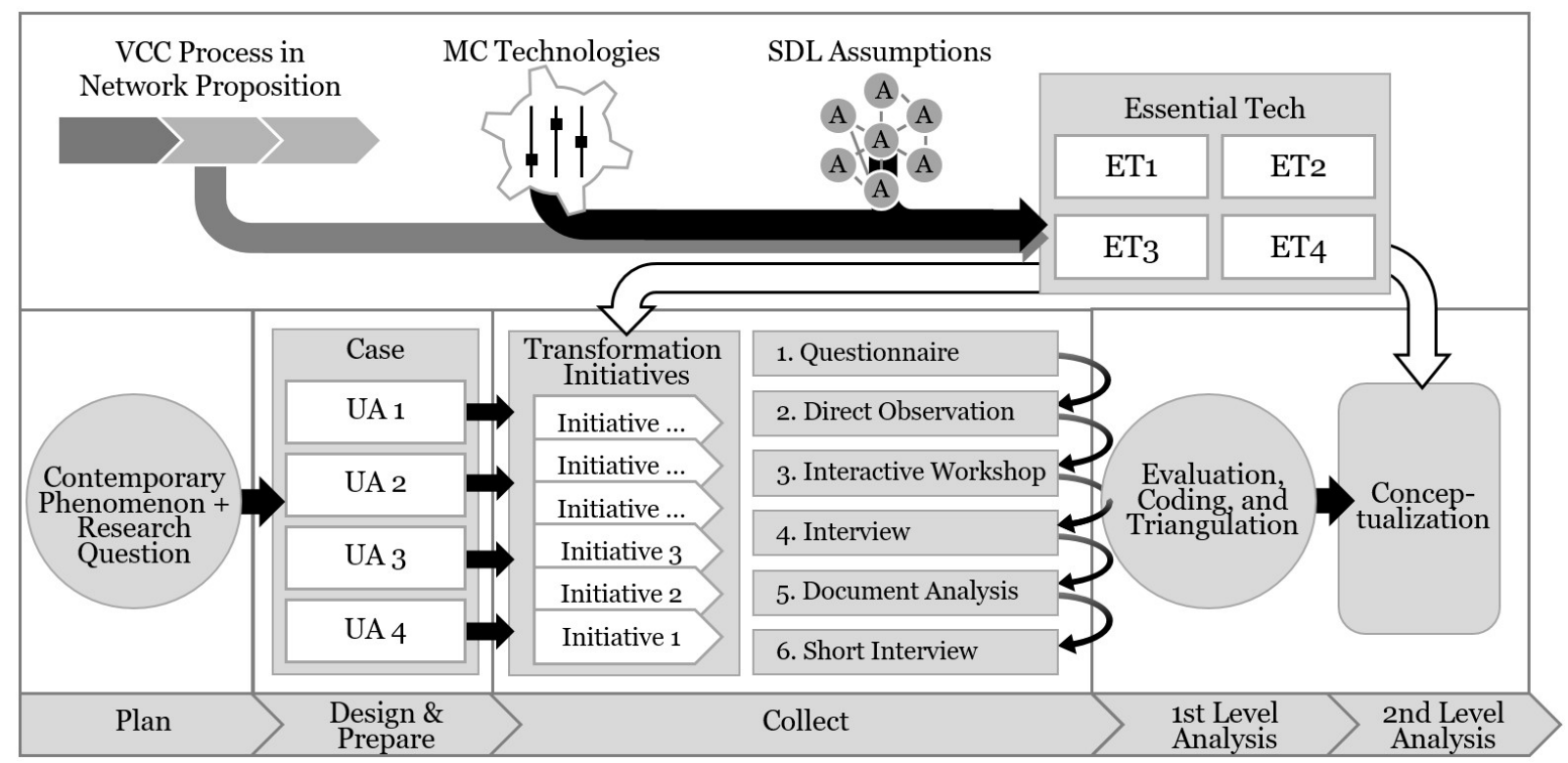

Figure 1. Research approach 
They are used to structure the transformation initiatives of the UA in our case and to point out how they are approaching these technologies in their VCC network. In the final step (second level analysis), the impact and role of the essential technologies in the network VCC are investigated.

\section{The Case about the Transformation of VCC in a Network}

The following approach is used in the observed network. One of the first steps in the digital transformation of the VCC was to define a common goal and to formulate a vision which is shared by all partners in the network. The overarching process of the VCC in the examined A2A network was recorded. Six distinctive phases could be identified [12]: (I) customer contact, (II) requirements analysis, (III) build value chain and calculate, (IV) prototyping and feedback, (V) order and production, and finally, (VI) outbound logistics and project closure. Along the VCC process, the digitization demand was determined, investigating the current degree of digitization. Furthermore, digitization potentials were identified. The digitization demands and potentials were synthesized and prioritized in the network before the companies opted for individual and joint initiatives to implement IT solutions to support the VCC in the network.

This section describes what has been decided by the companies with regard to the four essential technologies and which initiatives have been taken to implement them.

\subsection{Service Configuration System}

One challenge in our ongoing case is the heterogeneity of services the companies offer. While two are producing tangible fabrics, the other two either alter the fabric or combine it with other fabrics. The classical interpretation of a product configurator as a re-combiner of physical parts was not suitable in this case and initially led to a negative reaction of some companies. In the first step, the units of configuration needed to be determined. We could confirm what was already indicated by the recorded VCC process in several interviews, namely that the configuration in the context will be multi-layered. Whereby the first level of configuration contains the requirements towards the textile. The second configuration level is the network (building a supply chain for a specific customer order). The third level is the internal service configuration per company, including the order of work steps performed by machines and humans. The last level is the configuration of parameters, e.g. detailed machine settings or instructions for humans. This makes it necessary to have a service configuration system ignoring the differences between tangible and intangible products which is closer to a process configuration approach.

All companies were asked which functionalities are most important for the configuration of solutions in their network. The questions in questionnaires and interviews were based on a reference model for product configurators [17]. We found, that some of the functionalities were equally important for all companies, especially configuring via requirements (like UV protection factor for textiles) or via parameters (e.g. width of the textile). In the case of some other functionalities, the answer strongly depended on the role of the company in the network and the complexity of the task. For example, the weaving factory saw no relevance in a messaging functionality while the textile finisher saw a very high relevance, according to their high need for information exchange. Additionally, the textile finisher (who often works with chemical processes) demanded the highest degrees of freedom in the configuration of all companies, which means that they cannot predefine all configuration steps and need the possibility to define new ones. The textile coater, as the company which often manages the network customer contact, set a stronger focus on the integration of the network customer into the service configuration system. The position of the companies in the network and thus the fact whether they interact with the network customer leads to different application scenarios of the service configuration system. The most important phases of the VCC process that the investigated companies want to support with the system are (II) requirements analysis, (IV) prototyping and feedback, and (V) order and production. In the early phase, direct input by the network customer is possible. In consideration of the different configuration levels and the different application scenarios along the VCC process, the network opted for two joint initiatives. One for the introduction of a requirements-based configuration, and one for the introduction of a supply chain and process configuration.

\subsection{Centralized Knowledge Base}

It is very noticeable that almost all functions of the service configuration system that have been rated as 
most relevant on average are about storing and retrieving valid configurations in the network. This emphasizes the importance the companies see in managing the knowledge in a cross-organizational manner. Due to the ETO character of the VCC process, we observed a high complexity in the interactions, including meetings in the production facilities with partners and customers for joint problem-solving. In the examined network, a very large number of different actors work together, as we realized in interviews, workshops as well as direct observations, e.g. in production. Different types of knowledge are integrated into the VCC process, starting with application scenarios of the textile, which are known to the network customer, material properties, which are known to the sales staff (studied chemists), and processing details affecting the textile, which are known to the production staff from experience. One of the companies stated, that a centralized knowledge base with the ability to grow and learn, would be the solution to their challenges. The other three companies have emphasized the ability to manage problemsolving across their organizations as the most important value contribution of the central knowledge base. The document analysis showed, that the knowledge is currently often non-digital or not machine-readable or stored in systems not accessible to other actors in the network (as discussed in [16]). Although the companies are strongly interwoven in their VCC and can be seen as strategic partners, they are also individual companies with their own processes and systems. As an approach to build a centralized knowledge base, they decided to launch two initiatives. One is about finding a routine to load the shareable data from their enterprise systems into the knowledge base, including agreements on common vocabulary, technical agreements (e.g. millimeters, newton, etc. as units for certain parameters), and a common data model. The other one is about finding a routine to load the shareable non-digital data into the knowledge base, e.g. to store input from customers or necessary textile test certificates from external service providers, but also to make internal legacy documents accessible.

\subsection{Analytics System}

The current VCC in the network is often characterized by ad-hoc processes to exchange information and to handle exceptions in prototyping and production, where the wrong decision can ruin a whole batch of a customer order and the work of several involved companies. The observed production processes lead several hundred meters of fabric through large production plants with different machine sections. Machine sections can be used, e.g., for the application of chemicals or paints, but also for flame laminating or the thermal fixation of textiles. This means that if an error occurs, e.g. shrinkage with subsequent tearing of the textile, the plant cannot be stopped without making the textile unusable. It is necessary to promptly find a solution to this situation. These ad-hoc processes can hinder the value creation by binding the human capacities in the network. The companies stated, that not only IT support for storing and transferring data is needed but also for decisionmaking in the network. Although the information gathered from the interviews indicated that the companies expected rapid solutions to complex problems from IT support, the response to the proposal to introduce analytics was cautious. Therefore, we used a method to identify analytics use cases [37]. We analyzed each phase of the network VCC process with each company and derived implementable use cases for data analytics. In total 134 individual use cases could be identified, which consist of the combination of actor, question, data, process phase, and data analysis method. The identified use cases are distributed unequally over the six process phases, whereby the phases of (II) requirements analysis, (IV) prototyping and feedback, and (V) order and production contain the most use cases and thus analysis potentials. An identified use case which occurred in the discussion is as follows: actor - salesperson and developer, question - which process configurations result from a certain requirements configuration, data - requirements and configuration data, process phase - (II), and data analysis methods - recommendations (e.g. based on cluster procedures). The insights the companies gained from using the method to identify analytics use cases allowed them to choose multiple analytics initiatives within the network. The first and highest prioritized initiative is a recommendation system that displays valid configurations from previous cases based on similarities of requirements. These analyses simplify the translation of customer requirements into the production processes in the network - something that human beings have had to do until now. However, the same logic can also be used to find valid solutions in production fault situations (e.g. shrinking fabric). The second initiative aims to support in customer contact and in the early phases of consulting, in order to find valid solutions through optical similarity. The last and weakest weighted initiative that was started aims at a business intelligence system which analyzes historical data in the entire VCC process for decision support.

\subsection{Shared IT Platform}

The IT landscape differs strongly in the investigated network, as interviews showed. The 
companies have different enterprise resource planning systems ranging from individual developments to known standard software variants. Some have production planning systems, product data management systems, or recipe management systems. In all data collection rounds, including direct observation and document analysis, it has become clear that the degree of digitization of the companies differs across the network. However, as we stated in an earlier publication [16], the strongest difference in digitization is not between companies, but between types of communication in our network. While all companies are rather well digitized internally (i.e. they have optimized themselves focal-centered), the communication between the actors in the network is less digitized. The major challenges the companies describe in their VCC are inconsistencies and necessary discussions in the synchronization of technical parameters in prototype development and production, non-automated data exchange and incomplete transfer of customer requirements. As a consequence of the heterogeneous IT landscape, different degrees of digitization, and discontinuous information flows in the network, the companies have decided to introduce a shared IT platform as a shared initiative. This platform then enables all actors to engage in the VCC, offers shared vocabularies, and synchronizes network activities through mutual transparency. In our case, the platform incorporates the other essential technologies to enhance VCC. The large joint initiatives like the shared IT platform were first identified by the companies and the individual smaller initiatives were identified as preparatory steps for the larger goal. The pattern was that the company leaders reached an agreement at the network level, implemented it in their own company, and then synchronized the network VCC.

\section{Discussion of Findings}

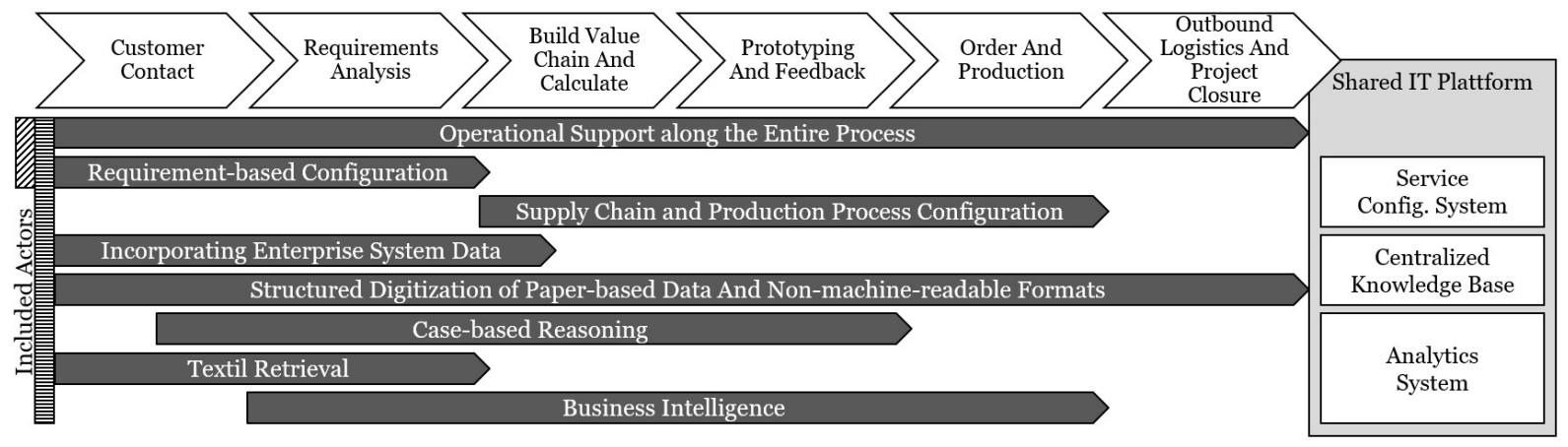


If information transfer is inhibited in knowledgeintensive service systems (e.g. because people do not want to share information) this has a negative effect on VCC in complex B2B networks [4], which is why IT support of knowledge exchange is essential. The centralized knowledge base enables all actors in our network to access this valuable resource with a high density. Thus, by increasing resource density, the central knowledge base has a positive effect on the network VCC by providing the best combination of resources for a particular problem [22]. Engagement platforms must evolve over time to reflect the dynamics of the VCC [29]. This means that the central knowledge base of our engagement platform must absorb re-configured solutions as new knowledge and thus act as a resource integrator towards the service configuration system. The companies stated in several interviews that through their knowledge-intensive work a learning platform is the only possible variant of such a system. This could be verified in the document analysis, where companies had to make handwritten adjustments to existing solutions over time.

The value of operant resources, such as knowledge, is determined by the extent to which they increase the ability of actors to generate new market offerings [18]. The re-combination of parts of known solutions to create new ones corresponds to Arthur's combinatorial evolution [2] which is considered a fundamental idea behind VCC [36]. In our case, the first test phases with a prototype showed that the reuse of existing solutions or solution fragments is one of the most important functions of the service configuration system for the companies, in order to be able to provide new solutions faster and in some cases possibly in better quality. This was confirmed by the companies in workshops and interviews. By accessing the centralized knowledge base, the service configuration system becomes a resource integrator and uses the operant resource of knowledge to combine it into new solutions, thus, contributing to innovation in the network VCC.

The use of analytics enables companies to gain previously unprecedented insights into customer preferences and requirements, but above all to enable them to recognize new business opportunities and innovations [5]. Data analysis is closely related to data collection and extraction [38] and thus to the efficient provision of relevant information. The analytics components already in use in our case indicate that analytics has an enhancing effect on both the central knowledge base and the service configuration system. For example, the knitting factory, which already uses case-based reasoning describes that now the use of the central knowledge base is much more effective. It is not only faster but also better results are often achieved. At this time, this approach is only applied to the company-level solution to obtain configuration recommendations. As in our example, the analysis system can be integrated into the VCC as an independent actor by calculating solution proposals and independently generating value-added contributions in the network.

Figure 3 summarizes the observed impact and role of the different essential technologies in our network and is thereby answering the second part of our research question. Introduction and first tests of the essential technologies show that the awareness for the VCC in the network increases and that the platform can become a host for the VCC. The platform is not only the engagement opportunity for all actors, but it is also a record for jointly found agreements. It records agreements regarding the content in the central knowledge base but also agreements of procedures on

Shared IT Plattform Hosting-Offering Shared Worldview

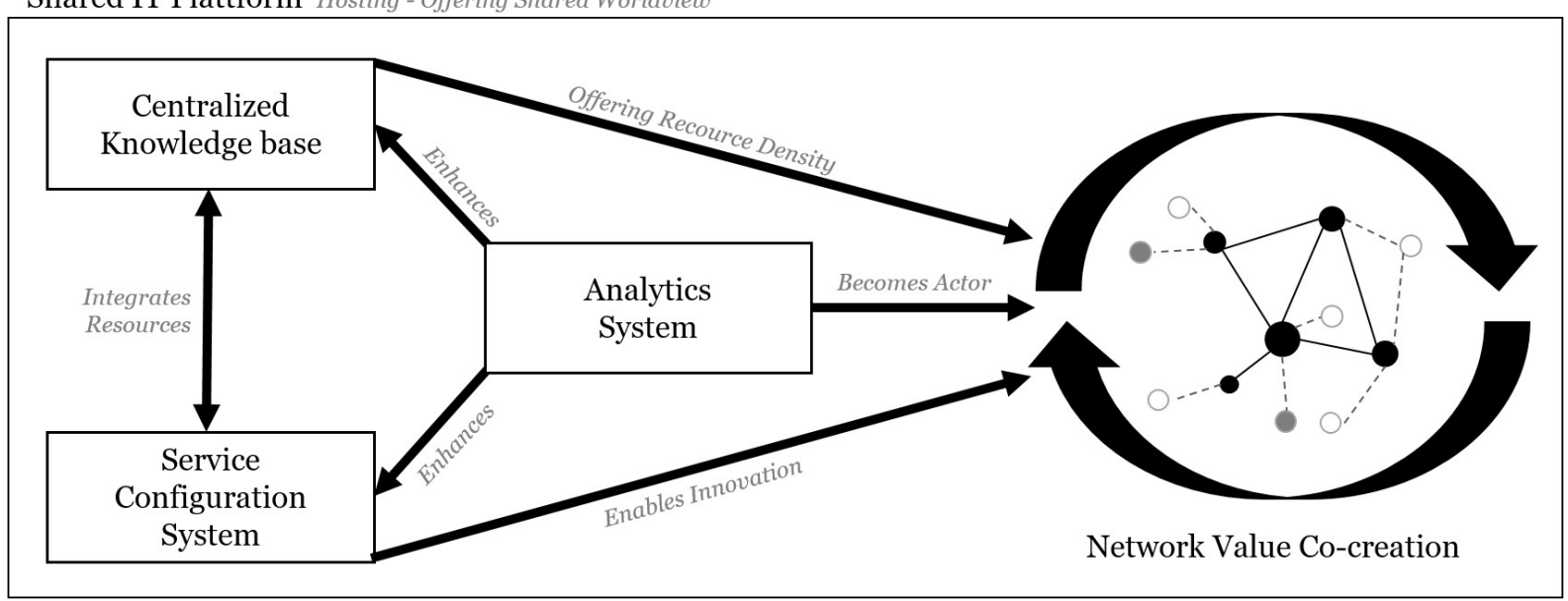

Figure 3. Impact and role of essential digital technologies 
how the VCC proceeds (e.g. via jointly defined user guidance and interface design in the application), thus offering a shared world view.

In addition, the use of these essential technologies reduces the ad hoc processes in our network, supporting the VCC by releasing human resources into higher-value activities (specifically stated by one company). To make these essential technologies work in a network, the scope of each part must be determined carefully per actor. Furthermore, the shared platform, which is open to all customers and can also accept new partners, is hosted at a neutral location at a regional textile research institute to underline the openness towards new platform members from the regional textile industry.

\section{Conclusion}

In this paper, we answer the question of how company networks introduce new technologies for enhanced VCC and how these technologies impact the network VCC. Therefore, we identified essential technologies to foster the VCC and conducted a case study in the German textile industry. The four companies in our case decided to jointly digitally transform their network VCC and therefore, to introduce the identified essential technologies. Our findings are that the companies chose a divide and conquer approach by launching small initiatives as a preparation for the overarching initiatives. They switch between network and company level during the implementation for synchronization. Furthermore, we have seen that the new technologies support the VCC network through resource density and enable innovation. A special role is assumed by the analytics system, which can actively intervene in the VCC process and enhance the effect of the other technologies. On the one side, our research has practical implications as it provides an approach on how networked companies, especially SME, can undertake the difficult task of digital transformation. On the other side, our research has implications for the research field of network VCC and we have contributed to the discussion on the impact and role of digital technologies on VCC. We have explored an empirically little studied field by focusing on VCC in B2B networks. In addition, we have addressed the technical foundations for the actor engagement in $\mathrm{MC}$ and bridged it to the VCC context. Nonetheless, our research has limitations. On the one hand, we have considered only a single case and, due to the specifics of the case, its generalizability could be affected. Although we believe that the role/impact of IT on VCC is transferable to networks with larger companies, the possibility of bigger companies to overpower smaller companies may hinder the willingness to implement such knowledge sharing approaches. In addition, the discussed technologies are not comprehensive and not all initiatives were completed at the time of writing so that there is still potential for further research. We hope to contribute to the research of network VCC and to provide our findings as useful insights for the digital transformation in SME networks.

\section{Acknowledgements}

The research in this paper was supported by a grant from the German Ministry for Research and Education (BMBF), project name: PROFUND, nr: 03ZZ0618C.

\section{References}

[1] Aarikka-Stenroos, L., and E. Jaakkola, "Value co-creation in knowledge intensive business services: a dyadic perspective on the joint problem solving process", Industrial Marketing Management 41(1), 2012, pp. 15-26.

[2] Arthur, W.B., The nature of technology: What it is and how it evolves, Free Press, New York, NY, 2009.

[3] Blecker, T., N. Abdelkafi, G. Kreutler, and G. Friedrich, "Product Configuration Systems: State of the Art, Conceptualization and Extensions", Maghrebian Conference on Software Engineering and Artificial Intelligence, (2004), $25-36$.

[4] Breidbach, C.F., and P.P. Maglio, "Technology-enabled value co-creation: An empirical analysis of actors, resources, and practices", Industrial Marketing Management 56(4), 2016, pp. 73-85.

[5] Chen, H., R.H.L. Chiang, and V.C. Storey, "Business Intelligence and Analytics: From Big Data To Big Impact", MIS Quarterly 36(4), 2012, pp. 1165-1188.

[6] Corbin, J., and A. Strauss, Basics of Qualitative Research Techniques and Procedures for Developing Grounded Theory, SAGE Publications, Inc., Thousand Oaks, CA, 2015.

[7] Dessart, L., C. Veloutsou, and A. Morgan-Thomas, "Consumer engagement in online brand communities: a social media perspective", Journal of Product \& Brand Management 14(1), 2015, pp. 28-42.

[8] Eze, S.C., and V.C. Chinedu-Eze, "Examining information and communication technology (ICT) adoption in SMEs - A dynamic capabilities approach", Journal of Enterprise Information Management 31(2), 2018, pp. 338356.

[9] Franke, N., P. Keinz, and M. Schreier, "Complementing Mass Customization Toolkits with User Communities: How Peer Input Improves Customer Self-Design*", Journal of Product Innovation Management 25(6), 2008, pp. 546-559.

[10] Franke, N., and F. Piller, "Key research issues in user 
interaction with user toolkits in a mass customisation system", International Journal of Technology Management 26(5/6), 2003, pp. 578-599.

[11] Franke, N., M. Schreier, and U. Kaiser, "The 'I Designed It Myself ' Effect in Mass Customization", Management Science 56(1), 2010, pp. 125-140.

[12] Grafmüller, L.K., S. Hankammer, S. Hönigsberg, and H. Wache, "Developing complex, mass-customized products in SME networks: Perspectives from co-creation, solution space development, and information system design", International Journal of Industrial Engineering and Management 9(4), 2018, pp. 215-227.

[13] Halinen, A., and J.-A. Törnroos, "Using case methods in the study of contemporary business networks", Journal of Business Research 58(9), 2005, pp. 1285-1297.

[14] von Hippel, E., "User Toolkits for Innovation", Journal of Product Innovation Management 18(4), 2001, pp. $247-$ 257.

[15] Hodges, N.J., and A.N. Link, Knowledge-Intensive Entrepreneurship: An Analysis of the European Textile and Apparel Industries, Springer, Cham, 2018.

[16] Hönigsberg, S., and B. Dinter, "Network Value CoCreation Goes Digital - a Case Study", 25th Americas Conference on Information Systems, (2019), 1-10.

[17] Hönigsberg, S., C. Kollwitz, and B. Dinter, "Designing a Reference Model for Digital Product Configurators", 14th International Conference on Wirtschaftsinformatik, (2019), 214-228.

[18] Hunt, S.D., "On the Service-Centered Dominant Logic for Marketing", Journal of Marketing 68(1), 2004, pp. 21 22

[19] Jaehne, D.M., M. Li, R. Riedel, and E. Mueller, "Configuring and operating global production networks", International Journal of Production Research 47(8), 2009, pp. 2013-2030.

[20] Kristianto, Y., P. Helo, and R.J. Jiao, "A system level product configurator for engineer-to-order supply chains", Computers in Industry 72(C), 2015, pp. 82-91.

[21] Legner, C., T. Eymann, T. Hess, et al., "Digitalization: Opportunity and Challenge for the Business and Information Systems Engineering Community", Business and Information Systems Engineering 59(4), 2017, pp. 301-308.

[22] Lusch, R.F., and S. Nambisan, "Service Innovation: A Service-Dominant Logic Perspective", MIS Quarterly 39(1), 2015, pp. 155-175.

[23] Mendikoa, I., M. Sorli, J.I. Barbero, A. Carrillo, and A. Gorostiza, "Collaborative product design and manufacturing with inventive approaches", International Journal of Production Research 46(9), 2008, pp. 2333-2344.

[24] Mittal, S., and F. Frayman, "Towards a Generic Model of Configuraton Tasks.", The International Joint Conference on Artificial Intelligence, (1989), 1395-1401.

[25] Möller, K., "Role of competences in creating customer value: A value-creation logic approach", Industrial Marketing Management 35(8), 2006, pp. 913-924.

[26] Ngugi, I.K., R.E. Johnsen, and P. Erdélyi, "Relational capabilities for value co-creation and innovation in SMEs", Journal of Small Business and Enterprise Development 17(2), 2010, pp. 260-278.

[27] Payne, A.F., K. Storbacka, and P. Frow, "Managing the co-creation of value", Journal of the Academy of Marketing Science 36, 2008, pp. 83-96.

[28] Prahalad, C.K., and V. Ramaswamy, "Co-Creation Experiences: The Next Practice in Value Creation", Journal of interactive Marketing 18(3), 2004, pp. 5-14.

[29] Ramaswamy, V., and F.J. Gouillart, The Power of CoCreation: Build It with Them to Boost Growth, Productivity, and Profits, Free Press, New York, NY, 2010.

[30] Ramaswamy, V., and K. Ozcan, "What is co-creation? An interactional creation framework and its implications for value creation", Journal of Business Research 84(3), 2018, pp. 196-205.

[31] Rogers, D.L., The digital transformation playbook: Rethink your business for the digital age, Columbia University Press, New York, 2016.

[32] Rudberg, M., and J. Wikner, "Mass customization in terms of the customer order decoupling point", Production Planning and Control 15(4), 2004, pp. 445-458.

[33] Sawhney, M., G. Verona, and E. Prandelli, "Collaborating to create: the internet as a platform for customer engagement in product innovation", Journal of interactive Marketing 19(4), 2005, pp. 4-17.

[34] Vargo, S.L., and M.A. Akaka, "Value Cocreation and Service Systems (Re)Formation: A Service Ecosystems View”, Service Science 4(3), 2012, pp. 207-217.

[35] Vargo, S.L., and R.F. Lusch, "Evolving to a New Dominant Logic for Marketing", Journal of Marketing 68(1), 2004, pp. 1-17.

[36] Vargo, S.L., and R.F. Lusch, "Service-dominant logic 2025", International Journal of Research in Marketing 34(1), 2017, pp. 46-67.

[37] Wache, H., C. Kollwitz, and B. Dinter, "Analytics Use Cases for Mass Customization - A Process-based Approach for Systematic Discovery", 52nd Hawaii International Conference on System Sciences, (2019), 5868-5877.

[38] Watson, H.J., "Tutorial: Big Data Analytics: Concepts, Technologies, and Applications", Communications of the Association for Information Systems 34(1), 2014, pp. 1247 1268

[39] Yin, R.K., Case Study Research and Applications: Design and Methods, SAGE Publications, Inc., Los Angeles, 2018.

[40] Zhang, L.L., "Product configuration: a review of the state-of-the-art and future research", International Journal of Production Research 52(21), 2014, pp. 6381-6398. 